\title{
Dynamic mode II delamination in through thickness reinforced composites
}

\author{
Dr Mehdi Yasaee ${ }^{a^{*}}$, Dr Galal Mohamed ${ }^{\mathrm{b}}$, Dr Antonio Pellegrino ${ }^{\mathrm{c}}$, Prof. Nik Petrinic ${ }^{\mathrm{c}}$, Prof. Stephen R. Hallett ${ }^{\mathrm{b}}$ \\ ${ }^{a}$ School of Aerospace, Transport and Manufacturing, University of Cranfield, Cranfield, \\ MK43 OAL, UK \\ *m.yasaee@cranfield.ac.uk \\ ${ }^{b}$ Advanced Composites Centre for Innovation and Science (ACCIS), University of Bristol, \\ Aerospace Engineering, Queen's Building, University Walk, Bristol, BS8 1TR, UK \\ ${ }^{c}$ Department of Engineering Science, Engineering and Technology Building, \\ Parks Road, Oxford OX1 3PJ
}

\begin{abstract}
Through thickness reinforcement (TTR) technologies have been shown to provide effective delamination resistance for laminated composite materials. The addition of this reinforcement allows for the design of highly damage tolerant composite structures, specifically when subjected to impact events. The aim of this investigation was to understand the delamination resistance of Z-pinned composites when subjected to increasing strain rates. Z-pinned laminated composites were manufactured and tested using three point end notched flexure (3ENF) specimens subjected to increasing loading rates from quasi-static $(\sim 0 \mathrm{~m} / \mathrm{s})$ to high velocity impact $(5 \mathrm{~m} / \mathrm{s})$, using a range of test equipment including drop weight impact tower and a split Hopkinson bar (SHPB).

Using a high speed impact camera and frame by frame pixel tracking of the strain rates, delamination velocities as well as the apparent fracture toughness of the Z-pinned laminates were measured and analysed. Experimental results indicate that there is a transition in the failure morphology of the Z-pinned laminates from quasi-static to high strain rates. The fundamental physical mechanisms that generate this transition are discussed.
\end{abstract}

Keywords: Through thickness reinforcement, damage tolerance, delamination testing, Z-pins, strain rate, impact

\section{Introduction}

Laminated composite materials have seen an increased usage across all transport sectors. The shift to use this lightweight material is necessary to help meet global environmental standards as well as reduce operational cost and improve performance. Composite materials provide exceptional specific stiffness and strength relative to their metal counterparts. Furthermore, they also possess excellent corrosive resistance and fatigue performance, yet a major drawback of this material is their lack of through thickness strength, which often results in disbond of the inter-laminar layers, also know as delamination. Composite materials are by design, capable of carrying in-service in-plane loads, however localized out of plane loading in forms of impact will result in delamination damage, which significantly reduces the performance of the component.

Many technologies have been developed over the years to address this problem, with through thickness reinforcement (TTR) being one of the highly successful methods [1]. A process known as Z-pinning is a popular method used to reinforce pre-preg composite laminates. Z-pining consists of inserting fibres or small rods into the composite material, reinforcing the thickness direction of the laminate. These small stiff, fibrous composite rods in the thickness direction bridge any newly formed delamination damage leading to excellent damage resistance capability [2]. 
Resistance of TTR composites to delamination has been subject to many studies, including quasi-static [2-4] and fatigue loading [5]. However, experimental investigations on the response of TTR composites when subjected to dynamic loading is limited and not well understood.

It has been shown for TTR composite laminates to have a direct dependence on strain rate when measuring the apparent mode II fracture toughness. Colin de Verdiere et. al. [6] reported a modest increase of approximately $26 \%$ in the initiation apparent $\mathrm{G}_{\text {IIC }}$ of tufted composite specimens. For Z-pinned composites the mode I apparent fracture toughness appears to reduce with an increase in loading rate as shown by Liu et. al. [7].

Very little literature exists on the mechanical properties and the delamination resistance of Z-pinned composites' dependence on strain rate (e.g. [8]). The aim of this investigation was to carry out a set of controlled mode II fracture toughness tests of a laminated composite reinforced in the thickness direction using carbon fibre reinforced plastic (CFRP) rods or Z-pins. These tests were carried out at loading rates from quasi-static up to $5 \mathrm{~m} / \mathrm{s}$ and full analysis of the composite response was made to conclusively show the effect of strain rate on the delamination resistance in un-reinforced and TTR epoxy based composites.

\section{Materials and specimen preparation}

Specimens were manufactured using IM7/8552 prepreg (Hexcel, UK) stacked with a sequence of $\left[(0,-45,0,+45)_{3 S}\right]_{S}$ to achieve a nominal thickness of $6 \mathrm{~mm}$. A $13 \mu \mathrm{m}$ PTFE film was placed at the mid plane to act as an artificial starter crack. The test procedure followed the standard 3 point bend end notched flexure (3ENF) [9] shown in Figure 1 with varying loading displacement rates $(\dot{\delta})$.

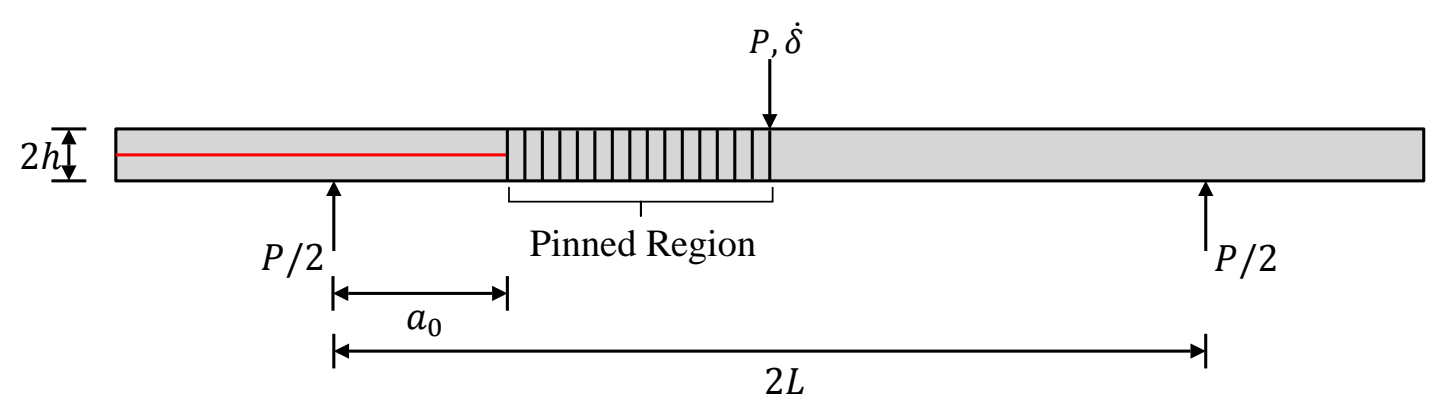

Figure 1 3ENF test setup

The Z-pinned specimens where pinned with T300 carbon/BMI pins arranged in a grid pattern with a spacing of $1.75 \mathrm{~mm}$, generating a nominal $2 \%$ areal density. To ensure consistency across specimens for both the control and the Z-pinned samples they were machined from a single plate.

Each specimen was machined to a nominal width of $20 \mathrm{~mm}$. The un-cracked part of each individual specimen was tested in 3 point bending (3PB) following the ASTM-790 [10] test standard to measure the flexural modulus $\left(E_{1 f}\right)$ of the material. The width $(B)$ and thickness $(2 h)$ of each specimen was measured at three different locations along its length to an accuracy of $\pm 0.05 \mathrm{~mm}$. For each specimen, a natural mode II pre-crack from the starter film was created using the procedure set out in ASTM-D7905 [9] to generate an initial crack length $\left(a_{0}\right)$ of $20 \mathrm{~mm}$ when positioned in the final test configuration. This resulted in $30 \mathrm{~mm}$ of uncracked laminate and reinforced region ahead of the crack for the control and Z-pinned samples respectively.

\section{Test procedures}

Increasing displacement loading rates from quasi-static $\left(8.3 \times 10^{-6} \mathrm{~m} / \mathrm{s}\right)$, to intermediate $(1-4 \mathrm{~m} / \mathrm{s})$ and high $(5.5 \mathrm{~m} / \mathrm{s})$ where carried out on three different test apparatus. The support roller half span $(L)$ was set at $50 \mathrm{~mm}$ with an initial crack length $\left(a_{0}\right)$ of $20 \mathrm{~mm}$ and support roller and loading nose diameter of $10 \mathrm{~mm}$ were set for all the tests. Using high speed photography with a minimum of 100,000fps for high loading rate tests and high definition imaging for quasi-static tests the displacement and the crack propagation for all tests were monitored. Each camera was set up to ensure on average a 12pixel per mm resolution, sufficient for full field strain measurements. 
The quasi-static 3ENF tests were carried out according to the ASTM-D7905 [9] standard with a loading displacement rates of $0.5 \mathrm{~mm} / \mathrm{min}\left(8.3 \times 10^{-6} \mathrm{~m} / \mathrm{s}\right)$. The load was measured using a calibrated $5 \mathrm{kN}$ load cell on a hydraulic Instron test machine. For these tests, the instability in the initiation of delamination means the maximum load corresponded to the critical load.

Intermediate loading displacement rate $3 E N F$ tests were carried out on an instrumented drop weight impact tower. For these tests a cylindrical loading nose was attached to the end of a calibrated piezo-electric load-cell. The loading displacement rate was varied by raising the entire impactor unit, weighing $6.21 \mathrm{~kg}_{2}$ to a specific height above the top surface of the laminate.

High loading displacement rate 3ENF tests were carried out using a modified Split Hopkinson Bar (SHPB) test procedure shown in Figure 2. This experimental procedure is similar to the impact bending test procedure carried out by Hallett [11]. A striker bar of length $L_{0}$, is accelerated using compressed air to strike an instrumented impactor bar of length $L$ with the same mechanical impedance and diameter. This impact then generates an impact duration of $2 L_{0} / c$, where $c=\sqrt{E / \rho}$ is the longitudinal wave speed in the bar. This transfer of kinetic energy then accelerates the impactor bar to a specific impact velocity generating the loading rate required to impact the specimen.

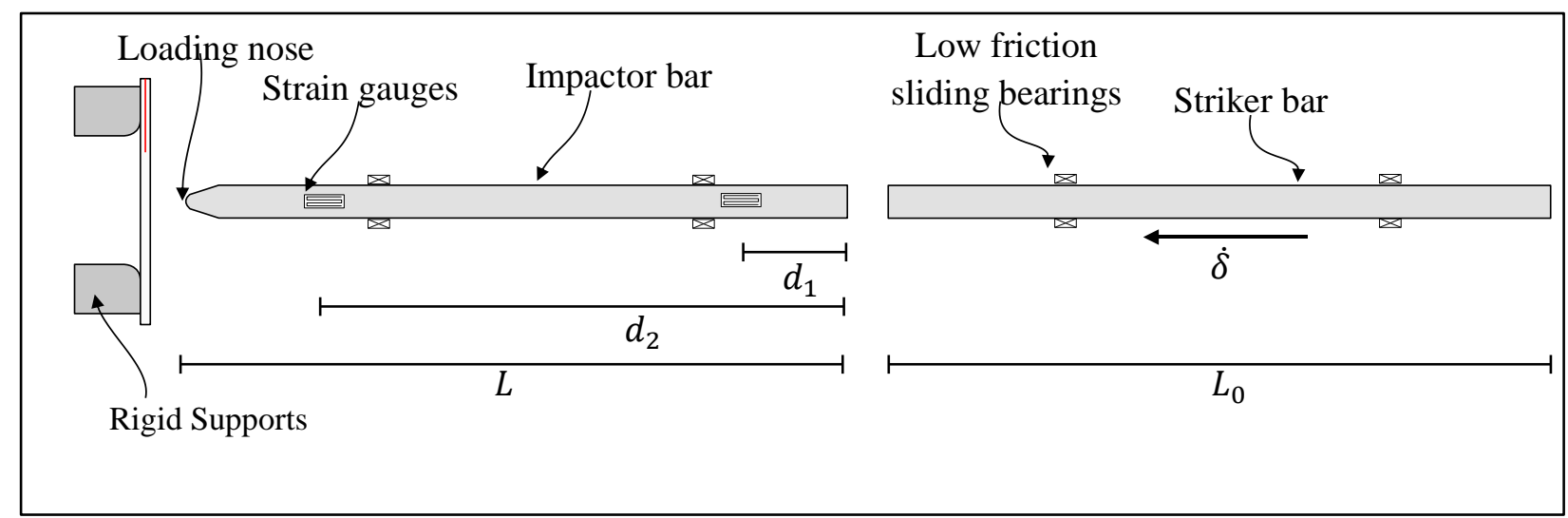

Figure 2 SHPB test setup

\section{Data reduction technique}

High frequency oscillations due to dynamic effects are inherent in all high rate tests. These dynamic effects are amplified as the loading rate increases therefore accurate critical load measurements are not possible [12] which will yield incorrect values of the materials fracture toughness. An alternative method proposed by Blackman et. al. $[12,13]$ use a compliance based approach to calculating the $G_{C}$ of the material since the CFRP laminates exhibit no observable strain rate dependency in their axial modulus $E_{11}$.

For this investigation $G_{I I C}$ is calculated using the displacement at the moment of delamination initiation. This displacement can be reliably measured using the high speed photography images from all the different loading rate test procedures. The compliance of the 3ENF specimen [14] is given by:

$$
C=\frac{2 L^{3}+3 a^{3}}{8 E_{1 f} B h^{3}}+\frac{3 L}{10 G_{13} B h}
$$

The term on the right includes the influence of through thickness shear which is dependent on the $h / L$ of the test setup. The mode II inter-laminar fracture toughness is then calculated using [15]:

$$
G_{I I C}=\frac{9\left(\frac{\delta}{C}\right)^{2}(a+0.42 \chi h)^{2}}{16 B^{2} E_{1 f} h^{3}}
$$




$$
\begin{gathered}
\chi=\left[\frac{E_{11}}{11 G_{13}}\left(3-2\left(\frac{\Gamma}{1+\Gamma}\right)^{2}\right]^{1 / 2}\right. \\
\Gamma=\frac{1.18 \sqrt{E_{11} E_{33}}}{G_{13}}
\end{gathered}
$$

Where the term $0.42 \chi h$ is the correction added to the length of the crack to account for the root rotation of the beam arms [15] and $E_{1 f}$ is the flexural modulus of the material which was measured for each specimen independently in the current experiments.

\section{Results}

\subsection{Quasi-Static - Data reduction method comparison}

The load-displacement plot of the control and pinned samples is shown in Figure 3a. The quasi-static flexural tests of all the samples produced an average flexural modulus, $E_{1 f}$ of $83.5 \pm 1.1 \mathrm{GPa}$. In Figure 3 the theoretical compliance using this flexural modulus average is plotted with $a=20 \mathrm{~mm}, B=20 \mathrm{~mm}$. Following the standard ASTM 3ENF test procedure the fracture toughness or $\mathrm{G}_{\text {IIC }}$ of the IM7/8552 was calculated to be $663 \pm 100 \mathrm{~J} / \mathrm{m}^{2}$. Using the compliance procedure described in section 4 and equation (2) the fracture toughness was measured to be $673 \pm 112 \mathrm{~J} / \mathrm{m}^{2}$. With only $1.5 \%$ difference between the two procedures, the compliance procedure can be accepted to produce correct values of the fracture toughness of the material and gives confidence to use for the high rate procedure.
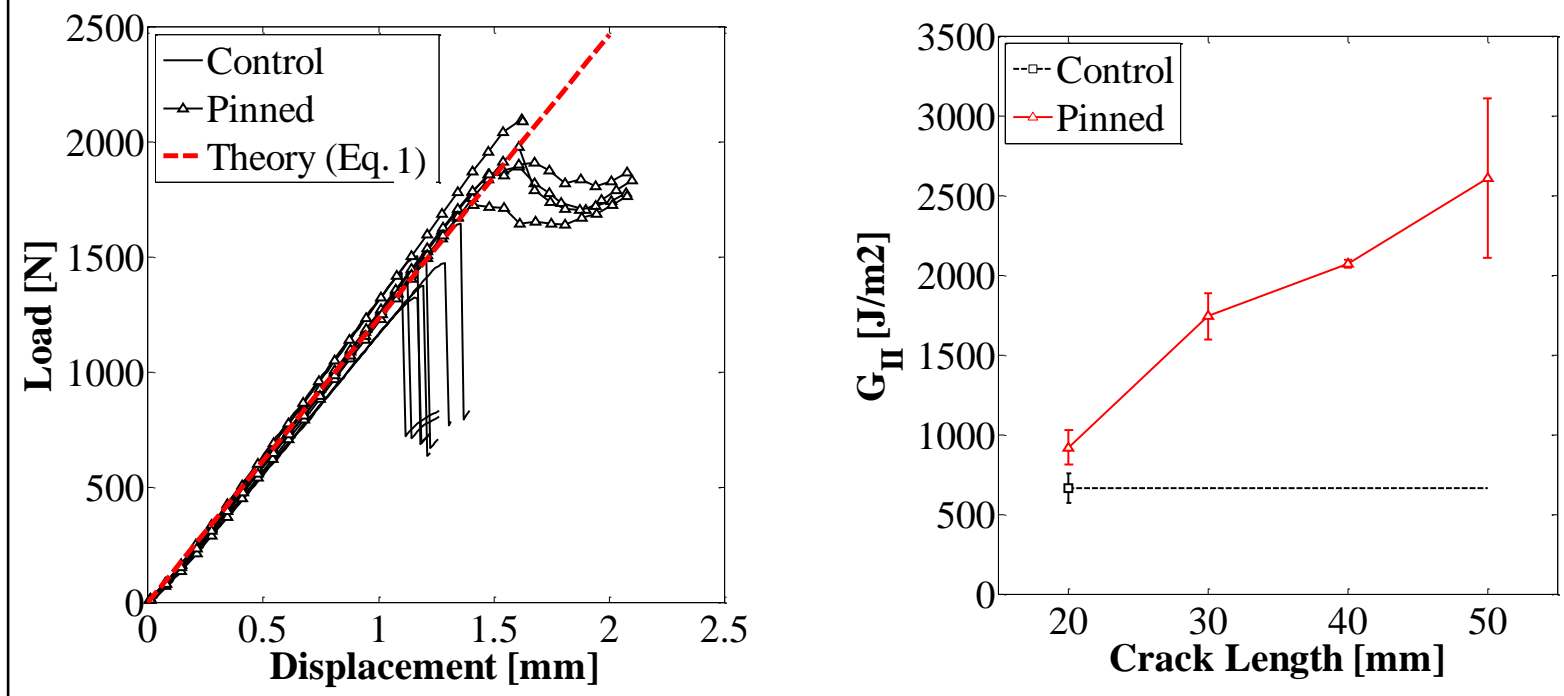

Figure 3 (a) Load-displacement for control specimens along with average compliance using equation (1) (b) Average R curve for control and pinned specimens

The average R curve for the control and pinned samples are shown in Figure 3b. The 3ENF tests typically produce a single critical strain energy release rate value due to the unstable nature of the crack. However, with the addition of TTR the crack is arrested and thus propagates stably in the TTR region. This produces an increasing $\mathrm{R}$ curve with crack length due to the development of the extrinsic bridging zone behind the crack tip. There is a minor increase in the average critical strain energy release rate at the moment of initiation $922 \pm 109 \mathrm{~J} / \mathrm{m}^{2}$ reaching a maximum strain energy release rate of $2613 \pm 499 \mathrm{~J} / \mathrm{m}^{2}$ at a crack length of $50 \mathrm{~mm}$. In this test configuration the maximum bridging zone length possible is $30 \mathrm{~mm}$, however the fully developed Z-pin 
bridging zone length is expected to be much longer than the $30 \mathrm{~mm}$ length, approximately between $40-60 \mathrm{~mm}$ [16]. The apparent fracture toughness increase of these tests agrees well with that previously reported in literature $[2,16,17]$.

\subsection{Load-displacement response}

The load-displacement plots for all the tests are given in Figure 4. As expected, increase in displacement loading rate $\dot{\delta}$ increases the noise in the load output measured producing an unclear critical load prior to delamination. It can be seen that the critical load cannot be taken directly from the load displacement responses necessitating the use of the compliance procedure to calculate the $\mathrm{G}_{\text {IIC }}$ of the specimens.

The load response appears to be constant in the control samples with increasing $\dot{\delta}$. However for the pinned specimens the critical load appears to increase with $\dot{\delta}$. Furthermore, as expected, the load drop is distinctly sharper for the control samples, whereas the pinned specimens still maintain significant residual interlaminar strength after delamination initiation.
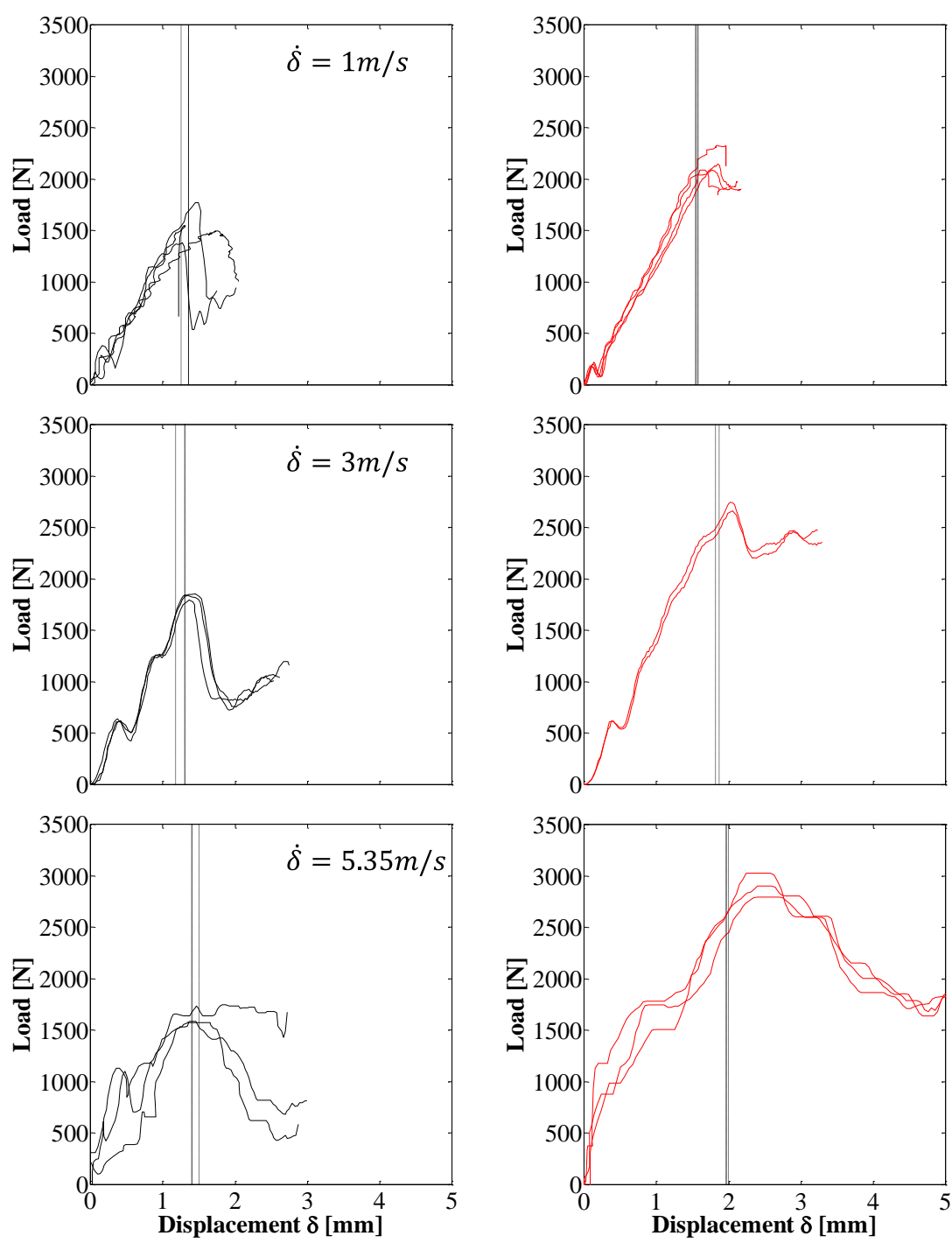

(a) Control

(b) Pinned

Figure 4 Load-displacement $(\delta)$ plots of for increasing loading displacement rate $(\dot{\delta})$, dashed lines indicate the displacement at which delamination initiated 


\subsection{Rate dependence of interlaminar fracture toughness}

The calculated $\mathrm{G}_{\text {IIC }}$ at the moment of delamination initiation against loading displacement rate $(\dot{\delta})$ is presented in Figure 5. The control samples produce a minor increase in the $\mathrm{G}_{\text {IIC }}$ with increase in loading rate, from $663 \pm 100 \mathrm{~J} / \mathrm{m}^{2}$ for quasi-static tests to $970 \pm 90 \mathrm{~J} / \mathrm{m}^{2}$ for $\dot{\delta}$ of $5.3 \mathrm{~m} / \mathrm{s}$. The pinned samples showed a very strong increase in $\mathrm{G}_{\text {IIC }}$ with increase in loading rate. With initiation $\mathrm{G}_{\text {IIC }}$ of $922 \pm 109 \mathrm{~J} / \mathrm{m}^{2}$ for quasi-static tests to $2002 \pm 64 \mathrm{~J} / \mathrm{m}^{2}$ for $\dot{\delta}$ of $5.3 \mathrm{~m} / \mathrm{s}$.

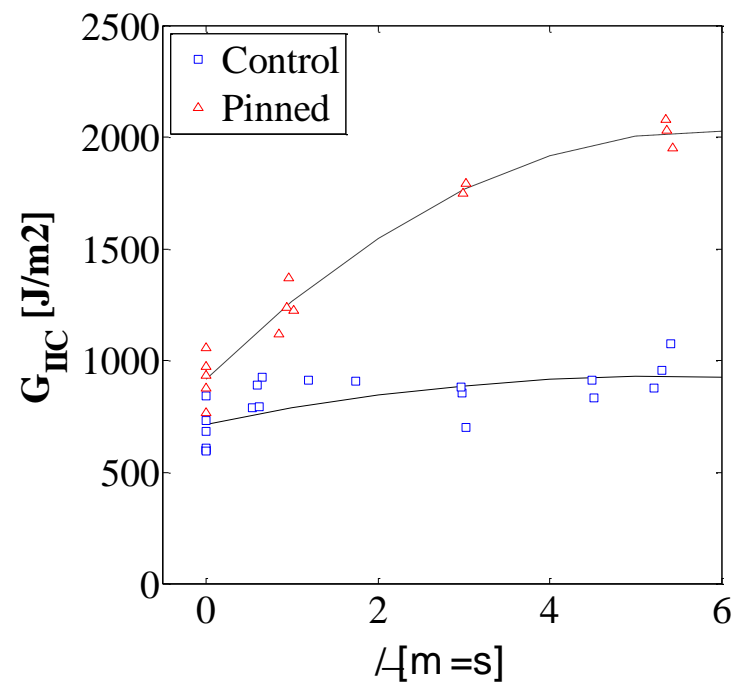

Figure 5 Gıc plots of for increasing loading displacement rate $(\dot{\delta})$

\section{Conclusions}

An experimental characterisation of a mode II delamination in a Z-pin reinforced and unreinforced laminated composite has been carried out with increasing strain rates. Tests were performed on standard hydraulic test machines for quasi-static tests, instrumented drop-weight impact tower for intermediate loading rates and a SHPB for high loading rates. Using a compliance based approach rather that the standard load based data reduction techniques, the $\mathrm{G}_{\text {IIC }}$ of the material was calculated at increasing strain rates.

The range of loading rates used in this investigation was from quasi-static to $\sim 5.3 \mathrm{~m} / \mathrm{s}$. The mode II fracture toughness of the composite was seen to have a minor increase from $663 \pm 100 \mathrm{~J} / \mathrm{m}^{2}$ to $970 \pm 90 \mathrm{~J} / \mathrm{m}^{2}$ confirming behaviours observed in literature of tests on thermosetting brittle epoxy composites, where either minor or no significant increase in $\mathrm{G}_{\text {IIC }}$ were reported $[12,18]$.

In contrast, with the presence of the Z-Pins, the mode II apparent fracture toughness showed a significant dependence on the displacement loading rate. It was shown that the initiation $\mathrm{G}_{\text {IIC }}$ increases from $922 \mathrm{~J} / \mathrm{m}^{2}$ to $2002 \mathrm{~J} / \mathrm{m}^{2}$ over the velocity range tested here.

This behavior may be attributed to the increased load transfer from the bulk material to the individual pins. The increased loading rate may harden the matrix and the Z-pin resin due to viscoelastic effects and thus the compliance of the pins is decreased. What this means, is that the length over which the Z-pins provide traction to the delaminated surfaces is shortened, meaning more Z-pins contribute to the fractured energy calculated at the initial crack length. It is expected that this contribution of fracture energy would reach an upper plateau with increasing strain rates, hence it would be important to experimentally characterize even higher rates in the future. However, with increasing loading rates, the influence of the kinetic energy of the specimen on the apparent fracture toughness calculations will become more significant and will have to be fully considered. 


\section{Acknowledgements}

The authors would like to acknowledge Rolls-Royce plc for their support of this research through the Composites University Technology Centre (UTC) at the University of Bristol, UK.

\section{References}

[1] Yasaee M, Mohamed G, Allegri G, Hallett SR. "Delamination resistance of through thickness reinforced composites," in 16th European Conference on Composite Materials, Seville, Spain, 2014.

[2] Yasaee M, Mohamed G, Allegri G, Hallett SR. "Mixed mode delamination resistance of Z-pinned composites - Testing and numericall modelling approaches," Engineering Fracture Mechanics, 2015.

[3] Lenzi F, Riccio A, Clarke A, Creemers R. "Coupon tests on z-pinned and unpinned composite samples for damage resistant applications," Macromolecular Symposia, vol. 247, pp. 230-237, 2007.

[4] Partridge IK, Cartie DDR. "Delamination resistant laminates by Z-Fiber pinning: Part I manufacture and fracture performance," Composites Part A: Applied Science and Manufacturing, vol. 36, no. 1, pp. 55-64, 2005.

[5] Pegorin F, Pingkarawat K, Mouritz AP. "Comparative study of the mode I and mode II delamination fatigue properties of z-pinned aircraft composites," Materials \& Design, vol. 65, pp. 139-146, Sep. 2014.

[6] Colin de Verdiere M, Skordos AA, Walton AC, May M. "Influence of loading rate on the delamination response of untufted and tufted carbon epoxy non-crimp fabric composites/Mode II," Engineering Fracture Mechanics, vol. 96, pp. 1-10, 2012.

[7] Liu H, Yan W, Yu X, Mai Y. "Experimental study on effect of loading rate on mode I delamination of z-pin reinforced laminates,” Composites Science and Technology, vol. 67, no. 7-8, pp. 1294-1301, Jun. 2007.

[8] Andrew Schlueter, Parab ND, Chen W. "Loading rate effects on mode I delamination of Z-pinned composite laminates," in Dynamic Behavior of Materials, Volume 1, Cham, B. Song, D. Casem, and J. Kimberley, Eds. Cham: Springer International Publishing, 2014.

[9] ASTM-D7905-14. "Standard Test Method for Determination of the Mode II Interlaminar Fracture Toughness of Unidirectional Fiber-Reinforced Polymer Matrix Composites,” ASTM International, 2014.

[10] ASTM D790-07. "Standard test methods for flexural properties of unreinforced and reinforced plastics and electrical insulating materials," ASTM International, vol. (2007)e1, 2007.

[11] Hallett SR. "Three-point beam impact tests on T300/914 carbon-fibre composites," Composites Science and Technology, vol. 60, no. 1, pp. 115-124, Jan. 2000.

[12] Blackman BRK, Dear JP, Kinloch a. J, Macgillivray H, Wang Y, Williams JG, Yayla P. "The failure of fibre composites and adhesively bonded fibre composites under high rates of test - Part I Mode I loading-experimental studies," Journal of Materials Science, vol. 30, pp. 5885-5900, 1995.

[13] Weeks CA, Sun CT. "Modeling non-linear rate-dependent behavior in fiber-reinforced composites," Composites Science and Technology, vol. 58, no. 3-4, pp. 603-611, Mar. 1998.

[14] de Moura MFSF, de Morais AB. "Equivalent crack based analyses of ENF and ELS tests," Engineering Fracture Mechanics, vol. 75, pp. 2584-2596, 2008.

[15] Wang Y, Williams JG. "Corrections for mode II fracture toughness specimens of composites materials," Composites Science and Technology, vol. 43, no. 3, pp. 251-256, 1992.

[16] Pegorin F, Pingkarawat K, Daynes S, Mouritz AP. "Mode II interlaminar fatigue properties of z-pinned carbon fibre reinforced epoxy composites," Composites Part A: Applied Science and Manufacturing, Aug. 2014.

[17] Cartie DDR, Troulis M, Partridge IK. "Delamination of Z-pinned carbon fibre reinforced laminates," Composites Science and Technology, vol. 66, pp. 855-861, 2006.

[18] Compston P, Jar P-YB, Burchill PJ, Takahashi K. "The effect of matrix toughness and loading rate on the mode-II interlaminar fracture toughness of glass-fibre/vinyl-ester composites," Composites Science and Technology, vol. 61, no. 2, pp. 321-333, 2001. 
2016-09-21

Dynamic mode II delamination in

through thickness reinforced composites

Yasaee, Mehdi

Springer

Yasaee M, Mohamed G, Pellegrino A, Petrinic N, Hallett SR, Dynamic Mode II Delamination in

Through Thickness Reinforced Composites, Fracture, Fatigue, Failure and Damage Evolution, Volume 8, Proceedings of the 2016 Annual Conference on Experimental and Applied Mechanics. http://dx.doi.org/ 10.1007/978-3-319-42195-7_13

Downloaded from Cranfield Library Services E-Repository 